Chapter 10

\title{
Production of Soybean-Derived Feed Material \\ Free from Salmonella Contamination: \\ An Essential Food Safety Challenge
}

\author{
Martin Wierup \\ Additional information is available at the end of the chapter
}

http://dx.doi.org/10.5772/66332

\begin{abstract}
Soybean meal is the world's most important source of protein for poultry and livestock. Due to frequent contamination of Salmonella, soy is since long unfortunately also found to be a high-riskfeed material for the introduction of Salmonella to the animal food production. This chapter focuses on the importance of biosecurity and hygiene in the production of soy-based animal feed. Those strategies and methods found to be effective tools for the production of a Salmonella-safe soy feed material in crushing plants and feed mills are reviewed and presented. It is also shown that the implementation of those methods at a limited cost can prevent animal feed from being the weakest food safety link in the food chain.
\end{abstract}

Keywords: Salmonella-contaminated feed material, food safety, soybean, crushing plant, feed mill

\section{Introduction}

This chapter focuses on the importance of biosecurity and hygiene in the production of soybased animal feed to avoid the spread of Salmonella to the animal food production making animal feed the weakest link in the food chain.

Soybean meal is considered as the world's most important source of protein for poultry and livestock [1]. In a corresponding way, Salmonella is a major food-borne pathogen, which globally is estimated to cause 93 million enteric infections and 155,000 diarrheal deaths each year [2]. Salmonella is most often detected in meat and animal-derived food products, which are the primary source of Salmonella when spread to humans following consumption of poultry, 
beef, pork, eggs, and milk. Vegetables and other food products can also be a source if contaminated with feces from Salmonella-infected animals [3-5].

In order to reduce the burden of human salmonellosis, efforts are directed to reduce the prevalence of Salmonella in the animal production including the animal feed. Like in humans, Salmonella is thus an orally acquired infection and the key route of transmission and Salmonella-contaminated feed is in both pigs and poultry found to be a major source of Salmonella [6, 7] which most likely is the case also for other food animal species.

Salmonella-contaminated soybeans and soybean meal are further found to be riskfeed materials of special importance for introducing Salmonella into the animal feed and the subsequent animal food chain [8]. Soy-based feed materials are of special importance because of not only being widely used but also being widely distributed, e.g., from South America to Europe. Possibly occurring Salmonella contamination in soy feed materials can thus be widely transmitted between countries and continents in case HACCP (Hazard Analysis \& Critical Control Point)-based program and associated control measures are not in place.

Following an overview of the usage of animal feed, the object of this chapter is to describe the strategies applied for producing Salmonella-safe soybean meal and compound feed based on a review of current knowledge and experiences.

\section{Usage of major feed materials}

Animal feed includes a variety of different feed materials primarily of vegetable and, to a limited extent, also of animal origin. Cereals and forages are the major feed components. In addition, fast-growing animals such as broiler chickens and fattening pigs, as well as highproducing animals such as dairy cows and laying hens, require more protein- and energy-rich feed components. The feed composition varies by animal species, type of production, and geographic regions. Statistics are available from different sources and in this chapter exemplified through data from Europe (EU28) provided by European Feed Manufacturers Federation [9]. For EU28 about 49\% (233 million tons) of the feed consumed by the livestock was grown and used on the farm of origin (mostly roughages). Of the feed material or compound feed purchased by livestock producers to supplement their own feed, compound feed accounted for $83 \%$ out of which the protein-rich cakes and meals accounted for $28 \%$ [9]. The total global compound feed production 2014 was 967 million tons out of which the major producers were China (19\%), USA (18\%), EU28 (16\%), and Brazil (7\%).

\subsection{Sources of protein-rich feed cakes and meals}

The access to protein-rich feed materials is essential in today's animal food production. The importance of protein-rich feed materials may be further strengthened in the light of the estimated need to increase the global food animal production by $>70 \%$ within the coming 40 years to feed the global population [10]. The demand for protein-rich feed is primarily met by a variety of products derived from vegetable protein. These products, often called cakes and meals, are generally by- or co-products from the food industry, e.g., from mills 
crushing plants for oilseeds, sugar-producing plants, distilleries, and starch factories. The special importance of the soybean crop also for the global food supply is that soybean oil is the world's most widely produced and widely consumed vegetable oil. Of the feed materials used by the EU/28 feed industry 2014, 28\% were cakes and meals and soy meal accounted for $60 \%$ [9]. Meat and bone meals from slaughter or rendering plants are currently banned in the EU and elsewhere since the BSE (bovine spongiform encephalopathy) crisis in the 1990s.

\subsection{Globalized feed supply}

In the same way as for food, the supply of animal feed for most countries is no longer solely based on domestic production. In a country like Sweden, only $72 \%$ of the non-forage feed materials for both swine and poultry are of domestic origin and for cattle the proportion is even lower (62\%). Soybeans are rarely grown in the EU as well as in several countries elsewhere with a similar climate in contrast to, e.g., USA. The EU feed industry is therefore dependent on importing vegetable protein, with soybeans or soya bean meals being the major products. These are imported mainly from South America where Argentina and Brazil are the major producers. According to the European Feed Manufacturers' Federation (FEFAC), the self-sufficiency in EU28 is 2\% for soybean [9]. The protein from soybeans is essential because it can only to a limited extent be replaced by, e.g., rapeseed meal because the latter contains higher levels of anti-nutritional factors.

\section{Feed production: special reference to soy}

\subsection{Crushing and crushing industries}

The oilseed processing involves the disaggregation of seeds, such as soybeans, palm kernels and rape and sunflower into crude vegetable oil, animal feed, and fiber. The crude oil is refined into food-grade, or may be used as an industrial or fuel feedstock. This process aims to release the oil and involves different methods for pressing or crushing the oilseed, the reason why these industries often are called "crushers." The crushing involves either the use of a screw/ expeller or hydraulic press between plates. Due to friction in the screw, the temperature is raised up to $130-140^{\circ} \mathrm{C}$, higher than in hydraulic press. Generally, the material in the crushing plants reaches $>100^{\circ} \mathrm{C}$ for $20 \mathrm{~min}$ [11]. The product after the crushing is called cakes which usually are ground to a meal. Solvent extraction is also done, typically with hexane, resulting in extraction meal which further is toasted or heat treated. The meals obtained are the typical feed ingredients and used under different names which reflect the different production methods applied that consequently affect their nutritional properties and often also the hygienic quality.

The crushing plants are either located in the seed production area or at the area of animal production or close to harbors. This is the case for soya beans and, e.g., Brazil's export to Europe is either soybean meal, crushed in Brazil or soya beans to be crushed in Europe. These products are transported by ships to the larger harbors of Europe for further transportation by smaller vessels or trucks to crushers or feed mills. To a certain extent, soya bean meal is also directly transported to and mixed into compounded feed at farms. 
From the point of risk management of Salmonella contamination of feed, it is interesting to note that the majority of feed and crushing industry is concentrated to a very limited number of large often globally operating companies. In the EU, more than $75 \%$ of the Europeancrushing capacity belongs to a small number of major international groups and the majority $(80 \%)$ of the oilseed producers ("the crushers") are organized in the EU Oil and Protein meal Industry; FEDIOL [12]. Another major player is COCERAL [13] composed of national feed trade organizations, indicating the international activity of the supply of feed materials to the food animal production industry. In the USA, NOPA [14] represents 12 companies including 57 plants that process soybeans, accounting for approximately $95 \%$ of all soybeans that are processed (crushed) in the United States.

\subsection{Feed mills-compound feed}

Compound feed is produced in feed mills. In contrast to the case of feed ingredients, the trade and distribution of the finished rations are usually regional. The feed is produced in large volumes and even a medium-sized plant can produce around 20 tons of compound feed per hour and usually operates $24 \mathrm{~h}$ /day and 5-7 days a week [15].

Although the size, age, and technical construction may vary between feed mills, they have similar functions in common (as illustrated in Figure 1). Their basic functions include handling and storage of incoming ingredients, the processing of the ingredients, and the conditioning and heat treatment of feed. These functions include different steps [16, 17].

After mixing, the mixture of feed ingredients is transported and stored as meal or mash feed in the finished-product bins, or for heat treatment in a conditioning and pelleting process which

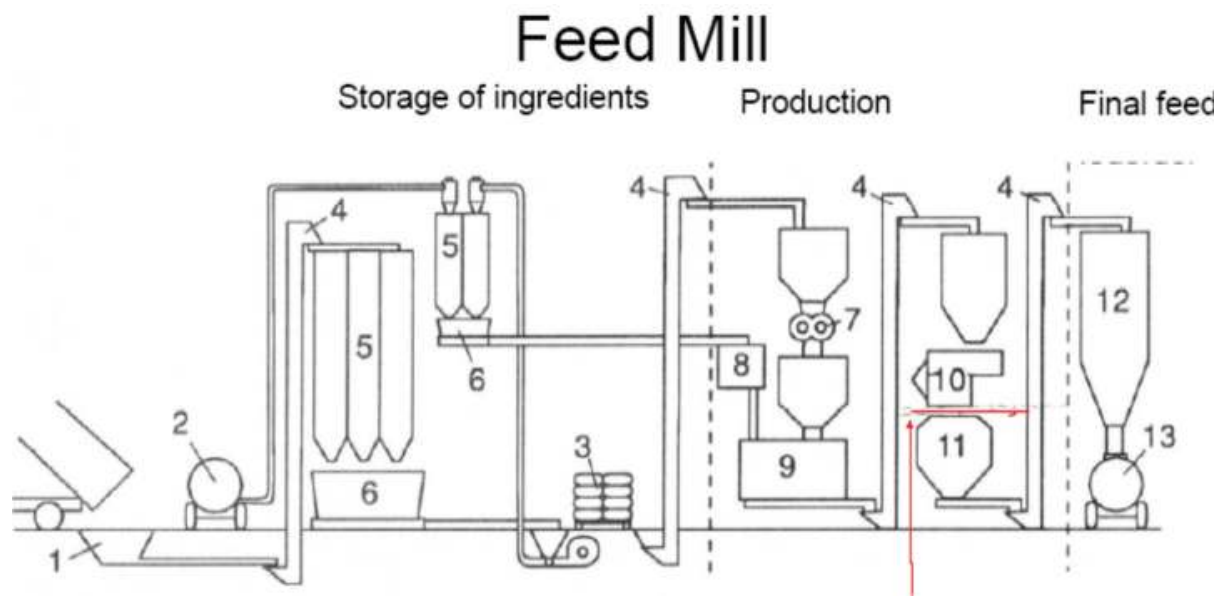

Figure 1. Schematic diagram of a feedmill. Source: Ref. [17]. 1. Intake pit for trucks, 2. Pneumatic intake for liquids, 3. Intake hopper for bagged ingredients, 4. Elevators, 5. Storage bins for ingredients, 6. Scales, 7. Grinder, 8. Pre- mix bins for premixes, vitamins, and so on, 9. Mixer, 10. Conditioner and pellet press, 11. Pellet cooler, 12. Storage bins for compound feeding stuffs, 13. Feed truck being loaded at out-loading gantry. Red arrows show the physical separation between "clean" and "nonclean" parts. 
are of special importance in relation to Salmonella contamination. Conditioning, followed by pelleting in a pellet press or expanding are the usual processing procedures performed in most feed mills when heat-treated feed is manufactured, although meals may also be heat treated, e.g., for poultry-breeding flocks in some countries.

Typically, the meal is introduced into the conditioner where steam is added to raise the temperature to a preset level. Conditioning and pelleting combined result in exposure of the feed to temperatures from around $50-90^{\circ} \mathrm{C}$. The moisture content of the feed after pelleting is approximately $15 \%$ and is cooled to ambient temperature and dried to approximately $12-13 \%$ as rapidly as possible to prevent condensation in the transport equipment and storage containers. After processing, the feed is stored a short period of time in silos or out-loading bins for compound-feeding stuffs before being transported to the farm. It is a feature of modern feed production that there is very limited storage capacity and most feed is dispatched within hours of production, so there is normally no opportunity for test and release programs.

The design and construction of the feed plant will to varying degrees allow effective physical separation of the clean (post-processing) and non-clean (ingredient storage and handling) parts of the production and likewise permit effective cleaning measures. The buildup of dust is a factor inherent in feed manufacturing. Therefore, adequate dust aspiration systems and vacuum line-cleaning equipment in the feed mill are important to keep the mill in a clean condition. It is also important that the aspiration of dust is not done with systems that contribute to the circulation of potentially Salmonella-contaminated particles in the mill.

\subsection{Oilseed meal in farm-level production}

Although a substantial proportion of animal feed is home-produced on farm, for certain sectors, and in particular for poultry, the majority of the feed is bought in as compound feed. For ruminants, the predominant part of the feed ration is generally home-grown or local forage and cereals. For pigs, around half of the feed is usually homemade, and in the UK the Meat and Livestock Commission has estimated that around $40 \%$ of feed produced for pigs is home-produced. Purchased feed is occasionally non-heat-treated meal, but is usually heattreated-pelleted feed.

Home-mixed feed is rarely pelleted and never heat-treated and should be considered as a risk when farmers as feed ingredient use soymeal of unknown Salmonella status. When available, by-products from the food industry such as whey, brewers, or distiller's grains and bakery waste are therefore included in non-poultry diets. This may involve the use of liquid feed systems.

\section{Salmonella contamination of feed}

\subsection{Evaluation of published date}

The result from those numerous studies found in the scientific literature and the gray literature on Salmonella in animal feed requires careful evaluation. As an example, a systematic 
review found that only 277 out of 5071 publications in English were considered to be relevant for the assessment of feeding management practice and Salmonella prevalence in live and market-weight finisher swine [18]. The sampling procedures usually differ and typically have a low sensitivity for detecting Salmonella contamination, and may well lead to underestimation of the level of contamination [19]. In the absence of harmonized-sampling procedures, results from testing of feed in different countries or in different studies are difficult to compare. The results of testing should be viewed as representing a minimum level of contamination. The same can be said for the data reported to the European Food Safety Authority (EFSA) from 19 Member States during 2008, in which Salmonella-positive findings ranged from 0 to $3.6 \%$ in cattle and pig feed up to $8.3 \%$ in poultry feed [20].

Results of various studies also need to be related to the actual Salmonella situation. The EUharmonized studies have thus revealed significant difference between Member States for the Salmonella status of poultry and swine and associated food products [20]. Similarly, there is a wide variation between the control actions applied in feed and animal production - from non-acceptance of Salmonella contamination to no actions taken.

Documentation of the importance of Salmonella in feed as well as of interventions requires that Salmonella contamination from other sources than feed can be excluded which is most easily achieved and performed in countries with a low level of Salmonella contamination as indicated in this review.

\subsection{Detection and sampling}

\subsubsection{Method for detecting and sub-typing}

Authorized methods for the isolation of Salmonella from feed and feed-associated samples follow standard bacteriological procedures, namely ISO 6579 and NMKL-71 [21]. The same methods are principally also applied in the food industry and on samples from different environmental as well as clinical sources. Modified semisolid rappaport vassiliadis (MSRV)-based methods have been shown to be suitable for testing of feed [22]. An official authorization also of their use for feed and foodstuffs as well as for samples from primary food animal production would offer significant benefits in terms of harmonization across the food chain. There may be strain variations and situations when existing Salmonella bacteria may be more difficult to isolate, but the above methods should in a reliable way detect Salmonella contamination in a sample as the level of competing flora is normally low.

Immunological (enzyme immune-linked sorbent assay (ELISA)) and molecular polymerase chain reaction (PCR)-based methods are available for an indirect and potentially faster detection of Salmonella contamination and identification of negative samples as a complement to the standard bacteriological procedures [21,23]. These are sometimes used to screen ingredients before processing or by primary poultry-breeding companies to test stored feed before placing on breeding farms.

However, direct methods with isolation of the microbe are needed for the sub-typing into serovars which is required for tracing and epidemiological studies. It should be highlighted that there is a risk that not all serovars present in a sample will be detected by these methods, 
if only one colony is selected for the final confirmation. A further sub-typing of isolated serovars, e.g., by pulsed field gel electrophoresis (PFGE) or variable number tandem repeat (VNTR) facilitates tracing and is useful when different strains of the same serovar or phage type occur [24]. A combination of antimicrobial resistance pattern and sub-typing result may add additional discrimination.

\subsubsection{Sampling methods}

A major challenge is how to design a suitable sampling protocol to substantiate freedom from Salmonella contamination to a defined level of confidence, in particular in large volumes of feed or feed ingredients, e.g., in a truck or a shipload. In contrast to a herd of animals, which is made up of a defined number of discrete sampling units - the individual animals, no corresponding unit exists for feed. Instead, a 25-g sample is often used as a sampling unit and "freedom" from Salmonella defined as absence in the number of specified samples examined. The problem is that the absence of Salmonella in the samples does not verify true Salmonella absence in a feed batch.

The testing of a selected number of samples in these situations should give a representative measure of the Salmonella contamination in the whole lot. The selection can be based on different methods such as simple random sampling, stratified random sampling, and systemic random sampling according to principles described in different ISO-documents and elsewhere. However, uncertainties exist, in particular relating to the uneven distribution of the low concentration of Salmonella contamination that is typically present in feed. Different statistically based models and methods have been worked out to address this challenge as described and reviewed by Biotracer [25]. This is an integrated EU project established in 2007 with one of the objectives to suggest sampling for tracking and tracing contamination of Salmonella along the feed chain. An EFSA opinion on microbial contamination of feed also highlighted the need for harmonized and validated methods [8].

Only a few countries are known to have implemented such sampling protocols, and in the absence of harmonized sampling or harmonized regulations for the control of Salmonella in feed or in feed production, there seems to be no agreed standard methods available for ensuring freedom of Salmonella, e.g., in a feed ingredient before used in feed production or of a compounded feed as a guarantee for a farmer. When a control is applied, testing for "freedom in a 25 gram sample" is often used, but freedom in one 25-g sample of feed gives very unreliable information on the contamination in the situations described above [26]. Foster found that testing around 60 negative 25 -g samples was required to conclude with $95 \%$ confidence that the contamination level is less than 1cfu per 526-g feed, which indicates the level of sampling that would be required to provide a meaningful result [27].

Testing of the final product alone is thus usually not sufficient to ensure Salmonella freedom. However, it is possible to ensure that a feed in practice is free from significant levels of contamination by Salmonella if instead the whole production process is controlled. A Salmonellafree feed could thus be defined as coming from a "Salmonella safe feed production," since the possible contamination of Salmonella is so low that it is very unlikely that it would result in an infection in animals consuming the feed. The official approval of feed mills could be based 
on the existence of an appropriate HACCP-based control and the use of associated strategies for interventions. This approach is successfully applied in Finland, Norway, and Sweden and is also found to be effective when applied for crushing plants for rapeseed [28] and soya beans [29].

If oilseed meal cannot be obtained from crushing plants under appropriate and effective HACCP program for the control of Salmonella, their products should be tested before introduction to the feed mill as applied in Sweden [30]. The surveillance of such high-riskfeed ingredients is based on a sampling procedure which takes into consideration an uneven distribution of Salmonella contamination and is designed to detect contamination in $5 \%$ of the batch with $95 \%$ probability [31]. The size of the analytical sample is $25 \mathrm{~g}$ and usually eight samples are analyzed, each consisting of 10 pooled sub-samples of $2.5 \mathrm{~g}$.

A representative sampling meets large practical difficulties in particular from large volumes of feed or feed ingredients that seemingly are inaccessible. To overcome these problems, it is advised to "sample in a moving stream" meaning that samples are taken when the commodity is circulated. This can be done manually or by the use of an automated inline statistical sampling device.

\subsection{Salmonella in different feed materials}

\subsubsection{Animal-derived protein}

Animal-derived protein has historically been found to be contaminated by Salmonella. From USA, several studies describe a high rate of contamination in by-products of animal origin. For example, 43 serovars of Salmonella were isolated from 175 (18\%) of 980 samples of such products from 22 states [32], or 28 serovars from 37 (18.5\%) of 200 samples of poultry and other animal by-products used in poultry feeds [33]. In a third study, 13\% of 5712 samples of bone meal, feather meal, fish meal, and egg products were Salmonella contaminated with 59 serovars [34]. Similar observations were made in Europe. The heavy contamination that could occur in these feed ingredients was demonstrated when up to 12 different serovars were isolated in a single contaminated batch, which in fact in Sweden in 1960 initiated an organized control program for Salmonella in feed, in particular for high-risk products such as animal-derived protein [35].

The source of the contamination appears to be carcasses from Salmonella-infected animal that are subject to an ineffective rendering process. Before the BSE crisis, animals that might have died from different infections, the so-called fallen stock, was also generally rendered, resulting in the risk for feed-borne spread also of other infections, and, e.g., anthrax was found to be spread to swine herds fed contaminated meat and bone meal [36]. The treatment in the rendering process $\left[133^{\circ} \mathrm{C}\right.$ for at least $20 \mathrm{~min}$ at 3 bar pressure to inactivate TSE (transmissible spongiform encephalopathies) agents] should destroy all incoming Salmonella. However, as for crushing plants and feed mills, there is a significant high risk of recontamination from a Salmonella-contaminated environment in the absence of effective hygienic routines [8] and leaking cooker seals can contaminate expellers with fluid from incompletely cooked material. The introduction of Salmonella through fish meal highlights a risk from proteins derived also 
from fish [4, 37], although it is uncertain if the fish themselves are the primary source of such contamination.

\subsubsection{Vegetable proteins}

Long-term experiences and data from several countries have highlighted and verified that vegetable proteins, cakes and meal, are frequently contaminated by Salmonella. In a comprehensive study from Poland, based on an annual examination of up to 80,000 batches of feed up to 15.0 and $15.4 \%$ of imported lots of soya bean and rapeseed meal were, respectively, found to be Salmonella-contaminated in 2005-2007 [38]. Salmonella is frequently also isolated from consignments of vegetable proteins which are tested before being used as feed ingredients in Sweden. During 2004-2005, 5250 pooled samples were analyzed from 795 consignments and $14.6 \%$ of the soybean meal and $10.0 \%$ of the rapeseed meal samples were contaminated [30]. When the majority of the imported soy was from South America, 20.1\% of the consignments were contaminated and even higher levels, up to $30 \%$, were regularly found in previous studies [39]. The frequent isolation of Salmonella from vegetable proteins is in agreement with several observations from different countries [8, 15]. However, a direct comparison of data from different studies is difficult due to differences in sampling and testing procedures [40]. This is illustrated in a Danish study where a low-sensitivity sampling program (i.e., one sample per batch/shipment of imported soybean meal) detected 35 isolates of Salmonella during 1994-2003 compared to 1086 isolates when 22 shipments were investigated during 2004 with a more intensified sampling [41].

Palm kernel and maize gluten are other feed sources of vegetable protein from which Salmonella also frequently is reported. Experiences indicate a lower prevalence and in one study $9 \%$ of 67 batches of maize meal and one of 127 batches of palm kernel meal were Salmonella-contaminated during a 2-year period (2004-2005) [30]. The EFSA zoonoses report data also point out oilseeds, e.g., soya bean products, as a risk factor for introducing Salmonella into the feed chain [20].

In summary, oilseed feed ingredients are often contaminated by Salmonella although it is difficult to compare the level of contamination between different studies due to variation in sampling and culture techniques applied. From an epidemiological point of view, there is a need to raise awareness in the industry that raw oilseeds and pulses may already be frequently contaminated before entering the crushing plants. There is also a need to reflect why in particular certain feed ingredients are frequently Salmonella contaminated, often with several serovars of Salmonella. Apart from in-house contamination in crushing plants and feed mills as well as contamination during transport and storage, studies indicate that, e.g., soybeans often are heavily contaminated already when entering the crushing plant. In a Norwegian plant-crushing-imported soybeans, dust samples from the arriving beans are taken upon arrival, as part of the HACCP control. During a 19-year period (1994-2012), Salmonella was on an annual average isolated from approximately $34(12-62) \%$ of the samples and in total 94 different serovars were identified [29].

Data on Salmonella contamination at the growing cite of soybeans seem to be lacking. However, it is logical to suggest that like for vegetables, soybeans may be contaminated by 
Salmonella-contaminated water used for irrigation or through manure used as fertilizer (i.e., "For example, see [42]"). This part of the Salmonella epidemiology requires further studies but indicates an infection cycle of Salmonella including links of fecal contamination from both humans and animals.

\subsubsection{Grain and forage}

The other major feed ingredients, grain and forage, are not primarily considered as high-risk products for Salmonella contamination of feed. When these feed materials are found to be Salmonella contaminated it is considered as a result of contamination from wildlife and during storage as further described below [43].

\section{Methods of prevention and control}

The prevention and control of Salmonella contamination of feed requires an integrated approach involving all links of the feed chain. Experiences have shown that there is no silver bullet that can meet all the challenges involved. Instead, a combination of precautions and actions is needed and an overall strategic approach is required to avoid being lost in details. Jones [44] has thus separated the control measures into three major strategies: prevention of contamination, reduction of multiplication, and procedures to kill the pathogen. It is helpful to consider an overall flow chart of the possible sources of contamination throughout the process [45]. A conceptual model is described for the pig feed chain, which can be adapted and applied to formulate a control program for the feed chain in question [15].

It should initially also be emphasized that it is possible to produce Salmonella-free feed under commercial and industrialized conditions as demonstrated by the fact that it is safe, even for broiler chickens. The young broiler is very sensitive to per-oral exposure to Salmonella and it is reported to be possible to become infected from ingestion of even few very Salmonella bacteria [46]. In the Scandinavian countries (Sweden, Norway, and Finland) with a long tradition of control of Salmonella in feed and broiler chickens, the incidence of Salmonella in broiler production is found to be very low when each flock is tested before slaughter [20].

\subsection{Feed mills and crushing plants}

Although many experiences on the control of Salmonella in feed mills have not been published in scientific literature, the major risks for Salmonella contamination of compounded feed are identified and also ways to minimize those risks, (i.e., "For example, see Ref. [39], several studies by Davies and coworkers $[19,43,47]$ as well as $\left.[8,15,44]^{\prime \prime}\right)$. The results of those studies are a good scientific base for advice in individual situations.

The data and advice in this chapter, which mostly focuses on feed mills, can be used also for crushing plants which work under similar hygienic conditions. This reflects that published data on hygienic routines and Salmonella control in crushing plants are surprisingly rare and contrasted with the importance of oilseed meals as a potential major source for the Salmonella contamination of feed mills and subsequently of food animals and of the food chain. 


\subsubsection{Major risk}

Long-term experiences have demonstrated that the major primary source for Salmonella contamination of feed mills and the compounded feed is Salmonella-contaminated feed ingredients, e.g., [48]. Monitoring of nine feed mills revealed that the intake pits were the most frequently contaminated sampling site and on average $24 \%$ of the samples were positive for Salmonella [47]. This risk is rather similar for all feed productions using vegetable proteins, which is a high-risk product for Salmonella contamination. In the EU, this in particular concerns soybeans or soybean meal out of which 98\% is imported from South America [9] and also domestically produced rapeseed meal as well as some animal-derived proteins when used. In all countries, there is thus a continuous risk for introducing Salmonella to the food chain via Salmonella-contaminated feed ingredients [8].

To minimize the risk described above, the most logical approach would be to prevent or eliminate Salmonella contamination as early as possible in the feed chain. In the case of the soybean meal, the focus of this chapter, Salmonella, should ideally have been already eliminated at the crushing or rendering plants. As described above, the process in these industries normally includes heat treatment that should readily eliminate Salmonella contamination and if recontamination is avoided, it would allow the production of Salmonella-free feed ingredients. However, available data indicate that it is generally not the case. Data on Salmonella contamination in crushing plants indicate the frequent occurrence of environmental contamination and cross-contamination, including re-contamination of heat-treated products [44, 49]. However, data from certain crushing plants also demonstrate that in spite of heavy Salmonella contamination of incoming soybeans (mean $30 \%$ of dust samples), it is possible to produce soybean meal which, based on testing and epidemiological experiences during several years, is found to be free from Salmonella [29]. Similar experiences exist from a rapeseed-crushing plant using the same control strategies as advised for feed mills [28].

The Salmonella-contaminated feed ingredients including soybean meal put an extra pressure on the feed mills to reduce the risk that incoming Salmonella is transmitted to the compounded feed. A strategy applied in Sweden to minimize this risk is to categorize the feed ingredients according to risk for Salmonella contamination. The high-riskfeed categories have to be tested negative for Salmonella contamination before being used for feed production. They are not allowed to enter the feed mill before a negative test result is at hand. Consignments found to be Salmonella contaminated are decontaminated by organic acids followed by re-testing with negative result before use [30].

As described below, heat treatment can be used to eliminate remaining Salmonella contamination. However, on an EU level, only $30-40 \%$ of the industrial feed is estimated to be heat treated [15], which emphasizes the importance of the Salmonella status of the feed ingredients. In the absence of heat treatment, Salmonella from contaminated feed ingredients easily is transmitted to the compounded feed. In such situations, the feed production does not include any specific processes aiming at reducing Salmonella contamination unless subsequently chemical treatment is applied. The observed decrease in the concentration of incoming Salmonella microbes in such production lines is primarily a result of dilution [19]. 
A second major source for Salmonella contamination at the feed mill is Salmonella-infected animal vectors which can contaminate feed ingredients during storage, at the intake pit as well as of the compounded feed. Salmonella was frequently (10 out of 51 samples) isolated from wild bird droppings from intake pit areas but also from warehouses and out-loading gantries and similar experiences are gained from other countries [47]. Salmonella typhimurium from wild bird is a particular concern. When feed materials are stored in open flat silos, rodents and cats may be additional sources for contamination of the feed material. Epidemiological experiences also suggest that birds, through fecal shedding, can infect animals via contaminated feed. The significance of this route was illustrated when virulent Newcastle Disease Virus, PPMV-1, in 1984 caused 22 outbreaks in chickens. It is widely accepted that the source of the PPMV-1 was poultry feed contaminated with feces from infected feral pigeons [50, 51].

Feed mills are thus attractive to birds as well as rodents if feed spillage and dust are not carefully and continuously removed from the environment. Such dust is thus often found to be Salmonella contaminated and wild birds, rodents, as well as humans can serve as vectors for contamination of the feed production [15]. To minimize these risks, the external environment of feed mills should be kept clean and in addition to rodent control, wild birds should be prevented from nesting and perching in roof spaces and gantries to avoid risk for direct and indirect fecal contamination of the feed.

In addition to the previous risks of external contamination, the cooler area is identified as probably the most important risk due to its potential to multiply a Salmonella contamination from incoming organisms that have survived the heat treatment process or have been introduced by the cooling air, if applied. The heat treatment associated with the pelleting process is thus also a potential hazard because steam is added to the feed. It is essential that this humidity as well as the heat is rapidly removed, which is done in the cooler by large volumes of air [44]. If the feed is not properly cooled, the cooling area can act as an incubator, allowing for fast multiplication of existing Salmonella microbes. Such contamination can not only directly contaminate the compounded feed but also establish a contamination in moist and fatty aggregates that can persist and act as a source for recontamination of the feed [47, 52, 53]. Experiences have shown that it is important to avoid the introduction of Salmonella by the cooling air. The air inlet to the cooling should be placed externally so that contamination by dust from, e.g., potentially Salmonella-contaminated feed ingredients, is minimized and the air is passed through a filter that removes dust and particles.

In order to avoid bacterial growth, experiences have demonstrated the need to avoid moisture in the whole-feed production system [43, 44]. Moisture can be caused by water cleaning, leakage, and condensation. In addition to the cooler area (see above), condensation of water may thus also occur in other places inside the feed transport systems as well as during storage [15, 44]. Experience from certain feed mills has also shown the existence of an in-house contamination indicated by the recurrent isolation of certain serovars of Salmonella during a period of many years in spite of various interventions [30]. This indicates that certain strains survive at unidentified spots or may be adapted to survive, e.g., by the help of bio-film formation [54].

There is also a need to develop methods for inspection and dry cleaning of the interior of the production line. Davies and Hinton [43] have highlighted the problems associated with 
inspecting certain coolers and the removing of internal coatings. The mills, in particular those of older age, are not constructed to meet hygienic requirements for cleaning and disinfection and access to critical sites to allow inspection and cleaning of the inside of production lines [43]. When found necessary, new openings for inspections are required as well as in critical situations modifications of the basic building constructions or equipment to overcome recurrent problems [55]. Decontamination of persistent contamination is demanding and requires special competence and in difficult situations dismantling of the whole process line has been found necessary $[16,43]$.

\subsubsection{Heat treatment}

Various studies have verified the Salmonella-reducing effect of heat treatment (i.e., "For example, see [11]"). It is reported that heating between 80 and $85^{\circ} \mathrm{C}$ for $1 \mathrm{~min}$ in most cases should eliminate Salmonella [53]. However, the elimination is dependent on the level of initial contamination and the set temperature and time range may not be reached to all parts of the feed [11]. Certain strains of Salmonella may also be more resistant to high temperatures which might explain the occurrence of Salmonella in feed following heat treatment [56, 57]. However, it is also reported that Salmonella contamination following heat treatment is most likely caused by internal contamination of the cooler [19].

The initial period after shutdown of the production before the intended temperature is reached is identified as a risk. Destruction or manual recirculation of the first feed produced before the set temperature is reached or during temperature dips is applied to avoid that contaminating Salmonella may survive due to too low temperature. Processes with automatic recirculation have been applied but found to be a risk for residual Salmonella contaminations. Another approach is therefore to automatically avoid the process to start until designated working temperature is reached.

It is important to note that the purpose of pelleting and the associated heat treatment is primarily to improve feed conversion and the handling qualities and feed intake, and not the hygienic feed quality although its hygienic potential early was recognized [58]. Temperature and time limits for the process are therefore guided to meet also nutritional requirements and exposure of the feed to too high temperature may have negative effects on certain feed ingredients such as amino acids and vitamins. As a complement to experimental data, empirical field data may give a more realistic result of the efficiency of heat treatment for eliminating Salmonella. Treatment at approximately $80-82^{\circ} \mathrm{C}$ for $30 \mathrm{~s}$ as generally applied by the feed industry in Sweden is found to result in Salmonella-safe poultry feed as described above. In summary, it is not possible to specify a minimum temperature and time range that under all conditions would be sufficient to eliminate contaminations of Salmonella in the industrial feed production [59]. Instead, as is applied in the food industry, monitoring of Salmonella and enterobacteriaceae contamination is used to ensure the efficiency of the process.

\subsubsection{Dry storage}

In the same way as it is important to prevent and reduce contamination of Salmonella at all steps of the feed production, it is equally important to prevent multiplication of possibly 
contaminating Salmonella microbes which can survive for considerable time in various materials [44]. Keeping all feed ingredients and the compounded feed under dry condition is therefore an essential requirement (i.e., "For example, see Ref. [44]"). In order to avoid microbial multiplication, grains should be dried to approximately $13-14 \%$ and oilseeds to $7-9 \%$ moisture content corresponding to a water activity of around $0.4-0.65$ [60].

\subsubsection{Chemical treatment}

Chemical treatment, mostly by organic acids, has been used to control Salmonella in feed production [8]. Such treatment seems to be used as a way to reduce or eliminate a Salmonella contamination from a batch of feed ingredients or as a general treatment of the feed fed to animals. The former use is applied, e.g., on feed ingredients found to be Salmonella contaminated before its use in feed production as described elsewhere in this document [30]. The latter use may have various reasons and in terms of Salmonella control it merely seems to be used in herds as a way to prevent intestinal colonization of Salmonella not only from feed but also from the environment [16].

Formaldehyde, which is found to be efficient for microbial decontamination of equipment and animal houses, is found to be effective with higher activity than acids also for decontamination of feed (i.e., "For example, see [61, 62]"). Formaldehyde has been used in combination with organic acids in order to achieve a synergistic effect allowing lower levels of formaldehyde and acids which, e.g., minimizes operator and possible food safety hazard, which is a reason why the use of formaldehyde in the EU so far in feed industry largely is limited to equipment and feeding systems. According to the feed-additive legislation, formaldehyde is only authorized at community level as preservative for skimmed milk for pigs up to the age of 6 months and for all species or categories of animals as silage additive [8].

\subsubsection{Dust removal and cross-contamination}

Dust and spillages are often found to be contaminated by Salmonella and therefore suitable for sampling (i.e., “For example, see Ref. [19]"). Programs for avoiding and removing dust and spillage also inside feed mill operations are found to be another essential requirement for avoiding the buildup of a Salmonella contamination that easily can be spread by cross-contamination.

The odds of contamination increase each time feed is handled [44] and it is reported that some ingredients may be handled up to 15 times before transport to the user [63]. Trucks used for the transport of manure on farms must certainly, e.g., not be used for transport of feed ingredients to crushing plants and feed mills. The logistics and management should thus be designed to avoid cross-contamination and separate storage of ingredients and the compounded feed, thus separating the so-called clean and unclean parts of the mill. This also applies to workers and visitors and in-house routines and the use of, e.g., protective clothes. It should be ensured that equipment and tools for service and repair are kept separate for clean and potentially contaminated areas. In some feed mills, external service people are not allowed to bring in their own equipment in order to avoid external contamination in critical places and accordingly, e.g., installation of second-hand-processing equipment from other mills is a major risk. 


\subsubsection{HACCP including monitoring}

The control of Salmonella in feed operation faces a continuously moving target. The risk for contamination varies over time but can never be excluded. An appropriate implementation of the control methods described above requires a careful planning as well as the design of a monitoring of Salmonella contamination. The monitoring should be based on the bacteriological examination for Salmonella of samples from dust and spillage [15, 19,44]. This process should follow the same principles as in food safety programs and be based on hazard analysis and critical control point principles, HACCP [8]. This should also include strategies for interventions when Salmonella contamination occurs and most important their implementation when required. Due to the risk for contamination of the compounded feed and the built-up of in-house contamination, it is important to endeavor to control Salmonella contamination whenever it is found [44]. The challenges to avoid Salmonella contamination in feed mills also apply for crushing plants, and the outline of a HACCP program for a crushing plant is described [28]. The HACCP program has to be adapted to each feed operation.

For reasons described above, sampling only of the compounded feed is inappropriate. This was highlighted in Sweden in 1993 when sampling of the compounded feed was unable to detect a contamination by Salmonella Livingstone in a feed mill in spite that serovars during a 7-month period was spread by the feed from the mill and repeatedly infected flocks of broiler chickens at 15 producers [64]. Based on this experience and following a poultry producer demand, the feed control was changed from sampling the end product to sampling at critical control points. The aim was to detect contamination of Salmonella as early as possible in the production process starting at the intake. The following control points were identified: top of bin for final feed (compound feed), room for pellet coolers, top of pellet cooler, dust from the production line dust aspiration system (filter), and from intake pit/bottom part of elevator for feed materials [48].This event also demonstrates that trace back investigations from Salmonella-infected herds can be used as part of a monitoring to detect the spread of Salmonella by feed [65].

The proof of an effective HACCP program in a crushing plant or a feed mill is that Salmonella contamination actually over time is identified in the unclean part of the production chain but not or rarely in the "clean areas" and final products [29, Figure 2].

Usually, most attention is paid to poultry feed because poultry is considered to be more sensitive to Salmonella exposure than, e.g., ruminants. Accordingly, heat treatment of feed is in some countries a legal demand only for poultry feed. However, feed for poultry and for other food animal species is often produced in the same mill. Although separate production lines including the transport to farms then should be applied, experiences have shown that cross-contamination easily occurs. In addition to experiences from cross-contamination with Salmonella, the risk for cross-contamination was typically visualized during the initial phase of the BSE crisis when feed intended for poultry and swine could end up in cattle feed. Other examples of cross-contamination are when medicals mixed into feed to one species have been observed in another animal species. A way to avoid such problems is to apply the same standard for the control of Salmonella in feed to all animal species. A risk assessment by EFSA has also stated that an overall requirement should be the final feed to all food animals is free 
from Salmonella [8]. When this is not the case, experience has shown that cross-contamination, e.g., between transports from feed mills to farms may occur if no through cleaning and disinfection procedures are applied. The importance of letting transport wagons as well as other equipment dry after cleaning and disinfection [43] is also emphasized.

\subsection{Farm production}

There appears to be very little literature concerning the risk for introduction of Salmonella to livestock as a result of home-mixing of feed although many studies are done in herds already being Salmonella infected [16]. In such studies, the possible effect of Salmonella-contaminated feed is usually measured only through the prevalence of Salmonella infections of animals being fed and are usually reported from countries and herds with a medium or high prevalence of Salmonella. Possible sources of the Salmonella infection in animals under such conditions are thus not only the feed but most likely to a much larger extent the result of direct and indirect transmission from neighboring animals although the initial source of introduction can have been the feed. The evaluation of the importance of Salmonella-contaminated feed in such herds and in particular when they are contaminated by several serovars of Salmonella (i.e., "For example, see Ref. [66]") requires comprehensive epidemiological studies. These need to be based on adequate monitoring for Salmonella and if possible the use of moleculargenotyping methods that allows for tracing of a Salmonella infection [67].

In a similar way as Salmonella-contaminating feed ingredients can be transmitted to the compounded feed in feed mills, this can also occur when such ingredients are used in farms. However, due to the difficulties to detect a Salmonella contamination as described above,

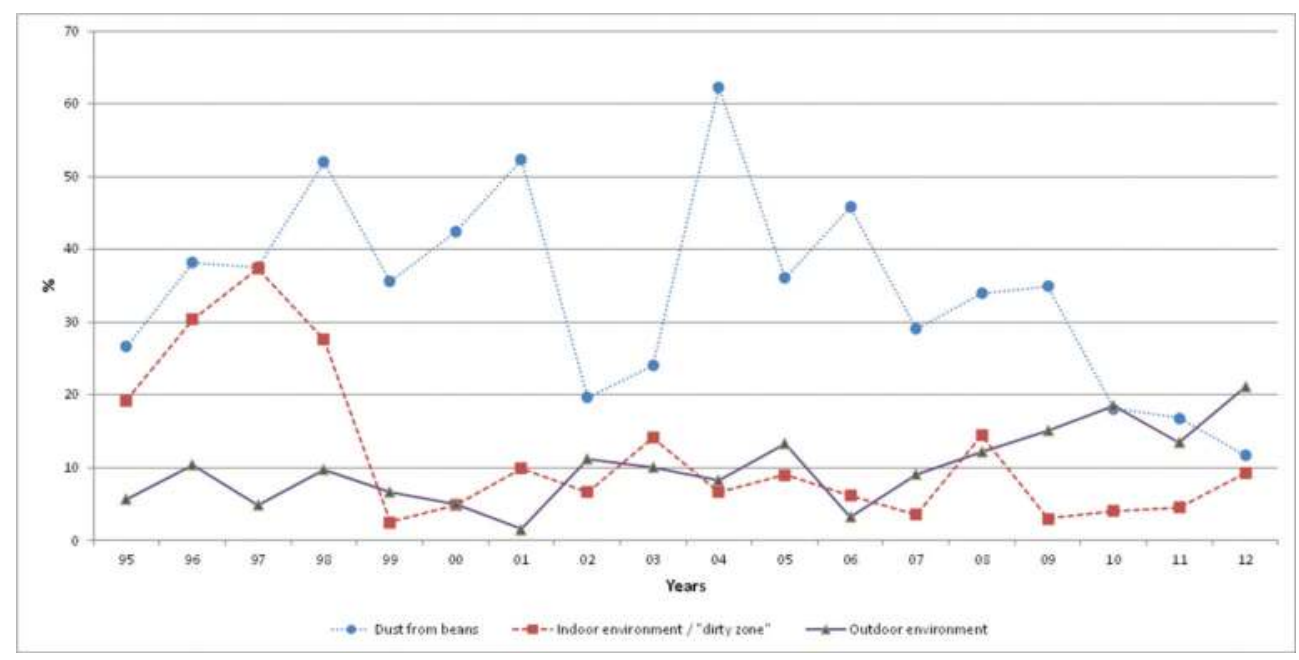

Figure 2. Isolation of Salmonella during 1994-2012 from a Norwegian plant-crushing-imported soybean (\% of total samples). During the whole period, Salmonella ( $0 \%$ ) was not isolated from the end products - not visible in the diagram. Source: Ref. [29]. 
there are so far in practice no available simple methods for farmers to ensure that bought-in feed ingredients or compounded feed is free from Salmonella. Such a guarantee can only be obtained when the feed products are produced in mill or crushing plant operating effective control of Salmonella. A quality control to ensure freedom of Salmonella contamination of feed ingredients and compounded feed on the market would enable farmers to safe-sourcing procedures to minimize the risk of introducing Salmonella through the feed and this is of high priority for high-risk products such as soybean meal.

\section{Significance of Salmonella in feed}

\subsection{Epidemiological aspects}

A striking example emphasizing the potential of contaminated animal feed to act as a source of Salmonella infections in humans occurred when Salmonella agona emerged as a public health problem in several countries due to the widespread use of contaminated fish meal that was imported as feed material. In the period 1968-1972, a rapid increase of human infections with S. agona occurred in the United States as well as in Europe [4]. Since then, S. agona is among the most prevalent serotypes in humans. It is estimated that the serotype up to 2001 caused less than one million human illnesses in the United States alone since it was introduced in animal feed in 1968 [4].

In older literature, Salmonella was sometimes referred to as a ubiquitous bacterium which, like, e.g., Escherichia coli, normally exists in the intestinal flora of animals and in the environment. This is a gross simplification and is not normally the case, in particular not for the major food animal species, and the occurrence of Salmonella in their environment and wildlife is usually a spillover effect from Salmonella-infected animals [68-70]. The epidemiology of Salmonella is characterized by a great potential to adapt to survival in certain animal species and in the environment. Although Salmonella under certain conditions also may multiply in environmental niches such as in the feed, their reservoir and major place for multiplication are infected animals (including wildlife) and humans following per oral ingestion. Salmonella is then excreted in feces during varying periods, often in large numbers in particular during the acute stage of the infection, e.g., $10^{6-7} \mathrm{cfu}$ per gram feces (i.e., "For example, see [71]").

As highlighted above, one of the major risk products for Salmonella contamination of the feed, the soybeans, is often heavily contaminated with a variety of serovars already when entering the crushing plant, which indicates links to fecal contamination from both humans and animals. Irrespectively of the primary source of this contamination, it is obvious that in the absence of effective Salmonella control of the feed probably for several decades, generations of food animals have been continuously exposed to Salmonella through their feed. This is likely to be the primary source of most of the Salmonella infection that is now resident in food animal breeding and production and in their environment in most countries.

Interestingly, the annual incidence of salmonellosis in humans in the industrialized world steadily increased from around the 1950s until it reached alarming proportions during the S. enteritidis pandemic in the late 1980s and early 1990s and annually in Germany alone was 
estimated to have caused two million human food-borne infections [72]. At that time, WHO (World Health Organization) concluded that the industrialization of food animal production had opened the door to the food chain for Salmonella.

The meat inspection procedures that were designed to ensure food safety by detecting lesions due to tuberculosis and zoonotic parasites such as Trichinella could not detect and eliminate carcasses contaminated with Salmonella. Apart from heat treatment, decontamination, and irradiation, there is still no effective means of ensuring Salmonella-safe food animal products for humans at the slaughter stage, or in the marketing of shell eggs, without effective control in primary production.

Following assessment of risk-mitigation options of Salmonella in swine and pork production [6] and in feed [8], a quantitative risk assessment concluded that in both breeder and slaughter pigs, infected incoming pigs and Salmonella-contaminated feed are the major sources of Salmonella [6]. A similar situation is the case for poultry. The importance of feed is further emphasized in that Salmonella-free feed is required to maintain the breeding animals free from Salmonella.

Data that document the importance of Salmonella in feed as well as of interventions are most easily achieved and performed in countries with a low level of Salmonella contamination. In other cases as described above, in-depth epidemiological studies are usually required. In such studies, it is also essential to consider the time factor for accessing consequences of introduction of Salmonella as well as of interventions [8]. The S. agona introduced to USA and elsewhere by fishmeal in the late 1960s as described above is today not considered to be being feed borne though it is still regularly found in vegetable proteins and finished feed in many countries. The lack of targeted studies is probably a major reason why feed as a source of introduction of new serovars of Salmonella in animal herds often is underestimated.

Very few data are available on the possible human health impact of feed as a source of contamination, which also should vary with the preventive measures applied in the whole feed and food chain. In one study from Denmark, it was estimated that $2.1 \%$ of domestically acquired human Salmonella infections during 1999-2003 could be attributed to feed-borne serotypes acquired through the consumption of domestic pork and beef and the dominating source of Salmonella was contaminated by imported soybean products [73]. However, apart from less intensive sampling of the feed material, major human pathogenic serovars (S. typhimurium and S. enteritidis) with a special ability to establish themselves in food animal populations were not included in the estimation.

The time factor also has to be considered when assessing interventions against Salmonella contamination in feed. In regions or farms with a high prevalence of Salmonella in animals, isolated interventions against Salmonella contamination on feed cannot directly be expected to result in a lower prevalence in animals or on carcasses after slaughter because other sources for the infection are relatively much larger and need to be addressed simultaneously $[6,74,75]$.

\subsection{Serovars involved}

The Salmonella isolated from feed or feed ingredients includes a wide range of serovars and to some extent also those serovars frequently causing disease in humans, e.g., in Sweden 38 
serovars of Salmonella were isolated from feed-associated sources during a 2-year period. Four $(10.5 \%)$ of the serovars isolated were among the 10 most common isolates of human cases of salmonellosis in the EU, and 30 (78.9\%) had also been isolated from human cases of salmonellosis diagnosed in Sweden during a 10-year period [30]. Salmonella serovars that frequently are causing infections in both animals and humans, e.g., S. enteritidis and S. typhimurium, are regularly isolated from feed [8]. When animals are exposed to such strains, they have a potential to multiply and spread on the farms and by trade to other farms as well as to humans following slaughter.

In another study of soybeans, 94 serovars of Salmonella were during a 19-year period isolated from soybeans dust samples during unloading of all shiploads from South America to a Norwegian-crushing plant. Those serovars included nine (90\%) of the EU 2012 top 10 serovars isolated from clinical cases of salmonellosis in humans, including major animal pathogenic serovars such as spp. Typhimurium and Enteritidis [29].

Only a limited number of the serovars normally cause disease in animals and the majority appears to be transient colonizers of the intestine. However, some of them can become adapted to certain animal species which facilitate their survival and spread. From the beginning, around 1980s, this was observed in Europe when a sharp increase in the prevalence of S. derby in swine occurred in several countries [76], probably because that serovar had become adapted to swine [77]. Another important example is S. enteritidis phage type 4 which during the 1980s appears to have adapted to poultry and infection of their eggs leading to a rapid spread in the world poultry production and a pandemic spread also in humans. S. enteritidis is since then the major Salmonella serovar-causing food-borne illness in humans [20,78]. Such events cannot be foreseen and because all serovars are considered to be potentially pathogenic for humans [8], there is little scientific support for a Salmonella-control policy in feed that is limited only to certain serovars. The importance of control of Salmonella in the feed and of the breeding animals is indicated by the fact that the existence of such controls probably was the reason why the Swedish poultry production was not involved in the worldwide spread of S. enteritidis in the late 1980s [79].

The relatively low occurrence in animal feed of serovars most frequently causing food-borne illness in humans has often been used as an argument against the potential importance of feed as a source of such infections. However, that argument is fallacious and seems to neglect that even an uncommon Salmonella following a per oral ingestion of an animal causes an active infection, often with a rapid multiplication of the microbe in contrast to being a passive contamination in the environment, feed, and in the subsequent food chain [44]. In fact, the same message was given already in 1969 by a United States Department of Agriculture (USDA) Committee on Salmonella, which concluded that this discrepancy in the assessment probably has contributed more than anything else to the fact that effective action has not been taken to control contamination of feed [80].

\subsection{Cost for control of feed}

In contrast to available data on how to prevent and control Salmonella contamination of feed, there is a considerable gap of published data on the actual cost of those actions [81]. It is 
currently also important to fill out that gap when considering that the costs, although unspecified, are sometimes used as an argument against implementing a control [73].

In a recent study, the total extra cost achieving a Salmonella-safe compound feed, when such a control is established, was estimated at 1.8-2.3€ per ton of feed [82]. Of that cost, $25 \%$ relates to the prevention of Salmonella-contaminated high-risk vegetable feed materials (mainly soybean meal and rapeseed meal) from entering feed mills, and $75 \%$ for measures within the feed mills. Based on the feed formulations applied, those costs in relation to the farmers' 2012 price for compound feed were almost equal for broilers and dairy cows $(0.7 \%)$. Due to less use of protein concentrate to fatten pigs, the costs were lower $(0.6 \%)$. These costs interestingly also include costly events to decontaminate a whole feed mill in case of serious contamination. However, because the cost is split on the large volumes produced the relative cost in relation to the feed price is surprisingly low. These estimations should be of general value since the feed production generally includes the same technical approach in most countries and the price for feed materials and compound feed follows the global prices on feed commodities. These limited costs suggest that recommendations by FDA (Food and Drug Administration) already in 1991 [83] as well as later [83] to enforce a Salmonella-negative policy for animal feed are realistic and economically feasible to prevent a dissemination of the pathogen to animal herds, their environment, and potentially to human food products.

\section{Conclusion and future perspective}

The initial strategy to prevent human food-borne salmonellosis at the consumer levels by good hygiene and safe cooking was insufficient [84]. Instead, the annual increase in the incidence of human food-borne salmonellosis that was generally observed since around 1950-1960 continued until the S. enteritidis pandemic in the end of 1980s initiated more active control of Salmonella in poultry in the EU and elsewhere [20, 78, 85]. In the EU, that control which focused on actions at the preharvest level is found to be the reason to the significant shift to a decreasing trend of the human incidence of salmonellosis [20]. However, due to less effective interventions in USA food-borne salmonellosis in 2011 is still one of the few food-borne pathogens for which illnesses have not significantly declined over the past 10 years [86]. In the EU, the control of Salmonella will be extended to other food animals, starting with pigs. In addition, the traditional meat inspection procedures are under review in the EU guided by the need to improve food safety against today's major food-borne zoonotic agents such as Salmonella, with addition of preharvest controls.

Substantial efforts will be required to reduce the Salmonella prevalence in herds of pigs and cattle. It would therefore be logical and probably most cost-effective to start this process by efforts to prevent animals from becoming infected through their feed, as well as through the breeding pyramid, and so apply the top-down approach that has been a successful concept for the control of Salmonella in poultry [7, 40]. Because important feed ingredients often are contaminated, stringent efforts to control Salmonella have to be implemented at the crushing plants and feed mills. A HACCP-based quality control system to ensure freedom of Salmonella contamination of feed ingredients and compound feed on the market would enable farmers 
to minimize the risk of introducing Salmonella through the feed. That approach would also be necessary to avoid Salmonella-contaminated feed jeopardizing their efforts to eliminate Salmonella at the farms.

As described in this review, long-term experience has shown that it is possible to produce feed that is free from Salmonella. In many countries, monitoring of Salmonella in feed and animals has also provided substantial experience on the epidemiology relating to the occurrence of Salmonella in feed. The cost for the production of Salmonella-safe feed materials and compound feed has also been estimated to be $<1 \%$ of the farmers' feed cost when such a control is established. The missing point seems to be the lack of stringent regulatory or economic incentives needed to combine improved monitoring with appropriate interventions. A proactive policy would help avoid urgent actions that might be imposed if new highly virulent serovars such as S. enteritidis should occur as an emerging threat to animal and public health in the future.

\section{Author details}

Martin Wierup

Address all correspondence to: martin.wierup@slu.se

Department of Biomedical Sciences and Veterinary Public Health, Swedish University of Agricultural Sciences, Uppsala, Sweden

\section{References}

[1] FAO - Animal production and Health, Protein Sources for animal feed industry, Expert Consultation and Workshop, Bangkok, 29 April-3 May 2002. Available from: http:// www.fao.org/docrep/007/y5019e/y5019e03.htm [Accessed: 2016-08-07]

[2] Majowicz S E, Musto J, Scallan E, Angulo F J, O'Brein S J, Jones T F: The global burden of nontyphoidal Salmonella gastroenteritis. Clin Infect Dis. 2010; 50:882-889.

[3] Gopinath S, Carden S, Monack D: Shedding light on Salmonella carriers. Trends Microbiol. 2012; 20:320-327.

[4] Crump J A, Griffin P M, Angulo F J: Bacterial contamination of animal feed and its relationship to human foodborne illness. Clin Infect Dis. 2002; 35:859-865.

[5] Pires S M, Vieira A R, Hald T, Cole D: Source attribution of human Salmonellosis: An overview of methods and estimates. Foodborne Path Dis. 2014; 11:667-676.

[6] EFSA: Scientific opinion on a quantitative microbiological risk assessment of Salmonella in slaughter and breeder pigs. EFSA J.2010; 8(4):1547. [80 pp.]. doi:10.2903/j.efsa.2010.1547

[7] Lewerin S S, Boquist B, Engström P, Häggblom P: The effective control of Salmonella in Swedish poultry. In: Mead G C, editor: Food safety in the poultry industry. Woodhouse publishing in food science and technology. Cambridge, UK: CRC Press; 2005; pp. 195-215. 
[8] EFSA: Microbiological risk assessment in feeding stuffs for food-producing animals. EFSA J. 2008; 720:1-84.

[9] FEFAC: Feed and food Statistical Yearbook 2015. Available from: http://www.fefac.eu/ publications.aspx?CategoryID=2061\&EntryID=629 [Accessed: 2016-08-07]

[10] FAO: World summit on food security; Rome 16-18 Nov 2009; Available from: http:// www.fao.org/wsfs/world-summit/en/ [Accessed: 2016-08-07]

[11] Himathongkham S, Pereira M G, Riemann H: Heat destruction of Salmonella in poultry feed: effect of time, temperature, and moisture. Avian Dis.1996; Jan-Mar; 40(1):72-77.

[12] FEDIOL. Available from: http://www.fediol.be/http://www.fediol.be/ [Accessed: 201608-07]

[13] COCERAL. Available from: http://www.coceral.com [Accessed: 2016-08-07]

[14] NOPA. Available from: http://www.nopa.org/oilseed-processing/ [Accessed: 2016-08-07]

[15] Binter C, Straver J M, Häggblom P, Bruggeman G, Lindqvist P A, Zentek J, Andersson MG: Transmission and control of Salmonella in the pig feed chain: a conceptual model. Int J Food Microbiol. 2011; 145 Suppl 1:S7-17.

[16] Wierup M: Salmonella in feed. In: Barrow P A, Methner U, editors. Salmonella in domestic animals, 2nd ed. Wallingford, UK: CABI International; 2013, pp. 377-398.

[17] Holmberg T, Häggblom P, Jonsson N, Larsson K: Swedish board of Agriculture in Technique and hygiene during feed production, 1993, pp. 10-25

[18] O'Connor A M, Denagamage T, Sargeant J M, Rajić A, McKean J: Feeding management practices and feed characteristics associated with Salmonella prevalence in live and slaughtered market-weight finisher swine: a systematic review and summation of evidence from 1950 to 2005. Prev Vet Med. 2008; 87 (3-4):213-228.

[19] Davies R H, Wales A D: Investigations into Salmonella contamination in poultry feedmills in the United Kingdom. J Appl Microbiol. 2010; 109 (4):1430-1440.

[20] EFSA: The community summary report on trends and sources of zoonoses, zoonotic agents, antimicrobial resistance and food- borne outbreaks in the European Union in 2008. EFSA J. 2010; 8(1):1496.

[21] Maciorowski K G, Herrera P, Jones F T, Pillai S D, Ricke S C: Cultural and immunological detection methods for Salmonella spp. in animal feeds-a review. Vet Res Commun. 2006; 30(2):127-37. Review.

[22] Koyuncu S, Häggblom P A: Comparative study of cultural methods for the detection of Salmonella in feed and feed ingredients. BMC Vet Res. 2009; 5:6.

[23] Maciorowski K G, Pillai S D, Jones F T, Ricke S C: Polymerase chain reaction detection of foodborne Salmonella spp. in animal feeds. Crit Rev Microbiol. 2005; 31(1):45-53. Review. 
[24] Xia X, Zhao S, Smith A, McEvoy J, Meng J, Bhagwat A A: Characterization of Salmonella isolates from retail foods based on serotyping, pulse field gel electrophoresis, antibiotic resistance and other phenotypic properties. Int J Food Microbiol. 2009; 129(1):93-98.

[25] Biotracer. Available from: http://www.biotracer.org/ [Accessed: 2016-08-07]

[26] Andersson G, Straver J, Löfström C, Lindqvist PA, Häggblom P: Sampling for traceability and conformance testing of Salmonella in animal feedingstuffs. Int. ProcSymp. on Salmonella and Salmonellosis, Saint-Malo Saint-Malo FRANCE, 2010; June, 28-30, pp. 69-72

[27] Foster E M: The control of Salmonellae in processed foods: a classification system and sampling plan. J Assoc Off Anal Chem. 1971; 54(2):259-266.

[28] Herland P J: Salmonella control of feed in the Swedish crushing industry; Proc. From Med-Vet-Net: Workshop on Salmonella control in poultry, from feed to farm; 13-17 March 2006 in Uppsala, Sweden, pp. 26-27; Available from: http://www.google.se/url?sa=t\&rc $\mathrm{t}=\mathrm{j} \& \mathrm{q}=\&$ esrc=s\&source=web\&cd=2\&ved=0ahUKEwiPj9zUqK_OAhVCOpoKHRfUDLg QFggmMAE\&url=http\%3A\%2F\%2Fs3.amazonaws.com\%2Fzanran_storage\%2Fwww. agronavigator.cz\%2FContentPages\%2F1852397210.pdf\&usg=AFQjCNEzC4sNq8m4ZN pN0Xww4eptUCUMQA [Accessed: 2016-08-07]

[29] Wierup M, Kristoffersen T: Prevention of Salmonella contamination of finished soybean meal used for animal feed by a Norwegian production plant despite frequent Salmonella contamination of raw soy beans, 1994-2012, Acta Vet Scand. 2014; 56:41.

[30] Wierup M, Häggblom P: An assessment of soybeans and other vegetable proteins as source of Salmonella contamination in pig production. Acta Vet Scand. 2010; 52:15.

[31] Ekbohm G: On the determination of the number of samples required for control of Salmonella (In Swedish), 1993; The Swedish Board of Agriculture.

[32] Pomery B S, Grady M K: Salmonella organisms isolated from feed ingredients; Proc US Livestock Sanit Ass. 1961; 65:449.

[33] Watkins J R, Flowers A I, Grumbles L C: Salmonella organisms in animal products used in poultry feeds, Avian Dis. 1959; 3:290.

[34] Morehouse L G, Wedman E E: Salmonella and other disease producing organisms in animal by products - a survey. J Amer Vet Med Ass. 1961; 139:989.

[35] Rutqvist L, Thal E: Salmonella isolated from animals and animal products in Sweden during 1956-1967. Nordisk Veterinaer Medicin. 1958; 10:234-244.

[36] Rutqvist L, Swahn O: Epizootiological and bacteriological investigations during the anthrax epizootic in Sweden 1956-1957. Nord Vet Med. 1957; 9:641-663.

[37] Clark G M, Kaufmann A F, Gangarosa E J, Thompson M A: Epidemiology of an international outbreak of Salmonella Agona. Lancet 1973; 2(7827):490-493. 
[38] Kwiatek K, Kukier E, Wasyl D, Hoszowski A: Microbial quality of feed in Poland. (In Polish with an English summary) MedycynaWeterynaryjna 2008; 64:183-188.

[39] Häggblom P:Monitoring and control of Salmonella in animal feed. NVI/WHOInternational coursee on Salmonella control in animal production and products, Malmö, Sweden,1993; Aug. 21-27. Ed. National Veterinary Institute, Uppsala, Sweden, pp. 127-137.

[40] EFSA (European Food Safety Authority) and ECDC (European Centre for Disease Prevention and Control): The European Union summary report on trends and sources of zoonoses, zoonotic agents and food-borne outbreaks in 2014. EFSA J 2015; 13(12):4329, 191 p. doi:10.2903/j.efsa.2015.4329

[41] Hald T, Wingstrand A, Brøndsted T, Lo Fo Wong D M: Human health impact of Salmonella contamination in imported soybean products: a semiquantitative risk assessment. Foodborne Pathog Dis. 2006; 3:422-431.

[42] Greene S K, Daly E R, Talbot E A, Demma L J, Holzbauer S, Patel N J, Hill T A, Walderhaug M O, Hoekstra R M, Lynch M F, Painter J A: Recurrent multistate outbreak of Salmonella Newport associated with tomatoes from contaminated fields, 2005. Epidemiol Infect. 2008; 136(2):157-165.

[43] Davies R H, Hinton M: Salmonella in animal feed. In Salmonella in Domestic Animals. 1st ed. Wray C, Wray A. CABI Publishing. Wallingford UK, New York USA, 2000; pp. 285-300.

[44] Jones F T: A review of practical Salmonella control measures in animal feed J Appl Poult Res. 2011; 20:102-113.

[45] Sauli I, Danuser J, Geeraerd A H, Van Impe J F, Rüfenacht J, Bissig-Choisat B, Wenk C, Stärk K D: Estimating the probability and level of contamination with Salmonella of feed for finishing pigs produced in Switzerland--the impact of the production pathway. Int J Food Microbiol. 2005; 100(1-3):289-310.

[46] Pivnick H, Nurmi E: The Nurmi concept and its role in the control of Salmonellae in poultry. pp. 41-70 in: Developments in Food Microbiology -1; R. Davies editor; 1982; Appl. Sci. Publ. Ltd. New York, NY.

[47] Davies R H, Wray C: Distribution of Salmonella contamination in ten animal feed mills, Veterinary Microbiology; 1997; 57:159-169.

[48] Malmqvist M, Jacobsson K G, Häggblom P, Cerenius F, Sjöland L, Gunnarsson A: Salmonella isolated from animals and feedstuffs in Sweden during 1988-1992. Acta Vet Scand. 1995; 36(1):21-39.

[49] Morita T, Kitazawa H, Lida T, Kamata S: Prevention of Salmonella cross-contamination in an oilmeal manufacturing plant. J Appl Microbiol. 2006; 101:464-473.

[50] Alexander D J, Parsons G, Marshall R: Infections of fowls with Newcastle disease virus by food contamination with pigeon faeces; Vet Rec. 1984; 115:601-602.

[51] Irvine R M, Aldous E W, Manvell R J, Cox W J, Ceeraz V, Fuller C M, Wood A M, Milne J C, Wilson M, Hepple R G, Hurst A, Sharpe C E, Alexander D J, Brown I H: 
Outbreak of Newcastle disease due to pigeon paramyxovirus type 1 in grey partridges (Perdixperdix) in Scotland in October 2006. Vet Rec. 2009; 165(18):531-535.

[52] Israelsen M, Hansen I D, Jacobsen E: Don't grow Salmonella in the pellet cooler. Feed Int. 1996; 34-38.

[53] Jones F T, Richardson K E: Salmonella in commercially manufactured feeds. Poult Sci. 2004; 83(3):384-391.

[54] Vestby L K, Moretro T, Langsrud S, Heir E, Nesse L L: Biofilm forming abilities of Salmonella are correlated with persistence in fish meal- and feed factories. BMC Vet Res. 2009; 5:20-25.

[55] Gabis D A: Environmental factors affecting enteropathogens in feed and feed mills. In Blankenship, L C, editor. Colonisation control of human bacterial enteropathogens in poultry, Academis Press, London, 1991; pp. 22-27.

[56] Kirby R M, Davies R: Survival of dehydrated cells of Salmonellatyphimurium LT2 at high temperatures. J Appl Bacteriol. 1990; 68(3):241-246.

[57] Habimana O, Møretrø T, Langsrud S, Vestby L K, Nesse L L, Heir E: Micro ecosystems from feed industry surfaces: a survival and biofilm study of Salmonella versus host resident flora strains. BMC Vet Res. 2010; 6:48.

[58] Swahn O, Rutqvist L: Pasteurisation of feed by heat pelleting. A way to reduce Salmonella? (Eng. summary). Sv Vet For Medlemsblad, 1957;9:377-383.

[59] van Asselt E D, Zwietering M H (2006) A systematic approach to determine global thermal inactivation parameters for various food pathogens. Int J Food Microbiol. 1957; 107(1):73-82. Epub 2005 Nov 7.

[60] Eisenberg S: Relative stability of selenites and selenates in feed premixes as a function of water activity, J AOAC Int, 2007; 90, pp. 349-353.

[61] Smyser C F, Snoeyenbos G H: Evaluation of organic acids and other compounds as Salmonella antagonists in meat and bone meal. Poult Sci. 1979 Jan; 58(1):50-54.

[62] Moustafa G Z, Zaki M M, Badawy E M: Hygienic control of Salmonella in artificially contaminated feed. Vet Med J Giza, 2002; 50(2):239-246.

[63] Ratcliff J: Pathogen control in feedmills. 2006; pp. 45-49 in Feed Processing and Quality Control. Technical Report Series. Am. Soybean Assoc., Int. Marketing, Southeast Asia, Singapore.

[64] Wierup M, Wold-Troell M, Nurmi E, Häkkinen M: Epidemiological evaluation of the Salmonella-controlling effect of a nationwide use of a competitive exclusion culture in poultry. Poult Sci. 1988; 67(7):1026-1033.

[65] Österberg J, Vågsholm I, Boqvist S, Lewerin S S: Feed-borne outbreak of Salmonellacubana in Swedish pig farms: risk factors and factors affecting the restriction period in infected farms. Acta Vet Scand. 2006; 47:13-21. 
[66] Marin C, Balasch S, Vega S, Lainez M: Sources of Salmonella contamination during broiler production in Eastern Spain. Prev Vet Med. 2011; 98(1):39-45.

[67] Löfström C, Eriksson J, Aspán A, Häggblom P, Gunnarsson A, Borch E, Rådström P: Improvement and validation of RAPD in combination with PFGE analysis of Salmonellaenterica ssp. entericaserovarSenftenberg strains isolated from feed mills. Vet Microbiol. 2006; 114(3-4):345-351.

[68] Henzler D J, Optiz H M: The role of mice in the epizootiology of Salmonellaenteritidis on chicken layer farms. Avian Dis. 1992; 36:625-631.

[69] Carrique-Mas J J, Breslin M, Snow L, McLaren I, Sayers A R, Davies R H: Persistence and clearance of different Salmonella serovars in buildings housing laying hens. Epidemiol Infect. 2009; 137(6):837-846. doi: 10.1017/S0950268808001568. Epub 2008 Nov 19.

[70] Quinn P J, Markey B K, Carter M E, Donnelly W J, Leonard F C: Veterinary Microbiology and Microbial Disease, Blackwell Publishing Company, 2003; ISBBN 0-632-05525-1, 106.

[71] Gutsman F. Layton H, Simiins, Jarlomen: Influence of antibiotic- supplemented feed; Am J Vet Res. 1976; 37:649-655.

[72] WHO: WHO-consultation on epidemiological emergency in poultry and egg salmonellosis. Geneva 20-23 March, 1989, WHO/CDS/VPH 89.92

[73] Hald T, Wingstrand A, Brøndsted T, Lo Fo Wong DM : Human health impact of Salmonella contamination in imported soybean products: a semi quantitative risk assessment. Foodborne Pathog Dis. 2006; 3:422-431.

[74] Alban L, Stärk K D: Where should the effort be put to reduce the Salmonella prevalence in the slaughtered swine carcass effectively? Prev Vet Med. 2005; 68(1):63-79.

[75] Carlson J C, Engeman R M, Hyatt D R, Gilliland R L, Deliberto T J, Clark L, Bodenchuk M J, Linz G M: Efficacy of European starling control to reduce Salmonellaenterica contamination in a concentrated animal feeding operation in the Texas panhandle. BMC Vet Res. 2011; 7(1):9.

[76] Wierup M: Control and prevention of salmonellosis in livestock farms. 16th Conf. OIE Regional Commission for Europe, Stockholm, Sweden, 28 June-1 July 1994, pp. 249-269.

[77] Wray C: Is salmonellosis a serious problem in veterinary practice? Vet Rec. 1985; 116:485-489.

[78] Sobel J, Hirshfeld A B, McTigue K, Burnett C L, Altekruse S, Brenner F, Malcolm G, Mottice S L, Nichols C R, Swerdlow D L: The pandemic of Salmonellaenteritidis phage type 4 reaches Utah: a complex investigation confirms the need for continuing rigorous control measures. Epidemiol Infect, 2000; 125 (1):1-8.

[79] Wierup M, Engström B, Engvall A, Wahlström H: Control of Salmonella enteritidis in Sweden. Int J Food Microbiol. 1995; 25(3):219-226. Review. PMID: 7654509 
[80] USDA, USDA Committee on Salmonella: An evaluation of the Salmonella problem, 1969, Publication 1683, National Academy of Science, Washington DC, Library of Congress Catalog Card Number 76- 60046113.

[81] ANON Analysis of the costs and benefits of setting a target for the reduction of Salmonella in slaughter pigs for EUROPEAN COMMISSION Health and Consumers Directorate-General SANCO/2008/E2/036 FINAL REPORT. 2010; FCC Consortium. Available from: http://www.google.se/url?sa=t\&rct=j\&q=\&esrc=s\&source=web\&cd=1\&v ed=0ahUKEwic_J6iq6_OAhXM2SwKHZAOBRAQFggcMAA\&url=http\%3A\%2F\%2Fec. europa.eu\%2Ffood $\% 2$ Fsafety\%2Fdocs\%2Fbiosafety_food-borne-disease_salmonella_ fattening-pigs_slaughthouse-analysis-costs.pdf\&usg=AFQjCNHtgImCWUPNOdtsJYpG HNeZwaVnbg\&bvm=bv.129391328,d.bGg [Accessed: 2016-08-07]

[82] Wierup M, Widell S: Estimation of costs for control of Salmonella in high-risk feed materials and compound feed. Infect Ecol Epidemiol 2014, 4:23496 -http://dx.doi.org/10.3402/ iee.v4.23496

[83] USDA 1969, USDA Committee on Salmonella: An evaluation of the Salmonella problem, Publication 1683, National Academy of Science, Washington DC, Library of Congress Catalog Card Number 76- 600461

[84] Mosel D A, Kampelmacher E H: Prevention of salmonellosis, Lancet, 1981; July 25, 208.

[85] WHO 1989, WHO-consultation on epidemiological emergency in poultry and egg salmonellosis. Geneva 20-23 March, 1989, WHO/CDS/VPH 89.92

[86] Batz M B, Hoffmann S, Morris Jr J G: Ranking the risks; The 10 pathogen - food combinations with the greatest burden on public health; University of Florida, Emerging Pathogen Institute, 2011; pp 1-68; http://epi.ufl.edu; [Accessed: 2016-08-07] 
